\title{
Testing EDS performance in ESEM
}

\author{
V.M. Dusevich, J.D.Eick
}

University of Missouri - Kansas City, School of Dentistry, Kansas City, MO 64155

Problems with EDS analysis in an environmental SEM (ESEM) are well known and are due to beam scattering and the creation of a so-called electron skirt. Analysis of homogeneous materials far from specimen's edges could provide agreeable results [1], but any deviations from these "ideal" settings will lead to considerable errors. Proposed means [2-4] are either not universal (for example, pressure could not be changed for wet specimens) or not widely tested. Therefore, utilizing EDS with ESEM, the microscopist should be aware of possible artifacts. This work presents results of testing EDS (Prism, PGT, NJ, USA) performance in a field emission ESEM (XL30, FEI, OR, USA).

A thin section (60-80 nm) of non-decalcified dentin on a copper grid was used as a test specimen. Dehydrated dentin is mostly a mineral (hydroxyapatite) and contains calcium. The specimen supplied high intensity characteristic radiation from bulk $\mathrm{Cu}$ and lower intensity $\mathrm{Ca}$ radiation. Existing tears and voids of the thin film (Fig. 1a) supplied marks for line scans and their edges were useful for evaluation of EDS spatial resolution. ESEM XL30 comes with a standard gaseous SE detector and special conical SE detector for working with EDS. This special detector decreases beam scattering but has free distance to specimen surface of only 1-2 $\mathrm{mm}$ and therefore is inconvenient for use with irregular specimens. Calcium line profiles, obtained with the standard detector (Fig. 1b), demonstrated that only at very low pressure ( 0.1 Torr) all details of the specimen were revealed on profile, and at 6 Torr no details at all were present. Contrary to these results, profiles obtained with the special detector (Fig. 1c), had useful information at all employed pressures, up to 8 Torr. Therefore, utilization of the special detector should be mandatory, especially while working with wet specimens, which are usually observed at 5.5-6.6 Torr. But even at lower pressures (1-2 Torr), results for the special detector are much better, and working with pressures below 1 Torr often could lead to charging and, consequently, to new types of EDS artifacts. However, even with special detector, beam scattering is significant. Figure 2 represents "tails" of $\mathrm{Cu}$ radiation registered on a carbon tablet, which could spread at 10 Torr to more than $250 \mu \mathrm{m}$ from the edge of the $\mathrm{Cu}$ grid, placed on the tablet. For the $\mathrm{Cu}$ grid placed on stainless steel, quantification of results on distances 10 and $50 \mu \mathrm{m}$ from the grid edge showed false presence of $11.6 \%$ and $6.7 \%$ of $\mathrm{Cu}$ at 6 Torr and $2.5 \%$ and $1.0 \%$ at 1 Torr. "Presence" of $\mathrm{Cu}$ became non significant at distances from the edge of the grid of about $250 \mu \mathrm{m}$ at 6 Torr and $70 \mu \mathrm{m}$ at 1 Torr (100 seconds counting time, spot 4). Ca K profiles, obtained from the edge of the thin film specimen (Fig. 3), were used for estimation of the spatial resolution for this specimen. It was better than $0.2 \mu \mathrm{m}$ in all cases, whether at high vacuum (Fig. 3a), or in wet mode at 2 Torr (Fig. 3b) or 6 Torr (Fig. 3c). With good spatial resolution, X-ray mapping (with its careful interpretation) is achievable in wet mode for at least major and intermediate components, as demonstrated on Fig. $4 \mathrm{a}$ for $\mathrm{Cu}$ in a bulk copper grid and on Fig. $4 \mathrm{~b}$ for $\mathrm{Ca}$ in the thin film.

[1] R.A.Carlton, C.E.Lyman, J.E.Roberts (2000) Microsc. Microanal. 6 (Suppl 2):790-791

[2] E.Doehne (1997) Scanning 19:75-78

[3] R.Gauvin (1999) Scanning, 21(6):388-393

[4] N.Gao, D.Rohde (2001) Microsc. Microanal. 7 (Suppl 2): 700-701

[5] This project was supported in part by NIDCR research grant DE09696 

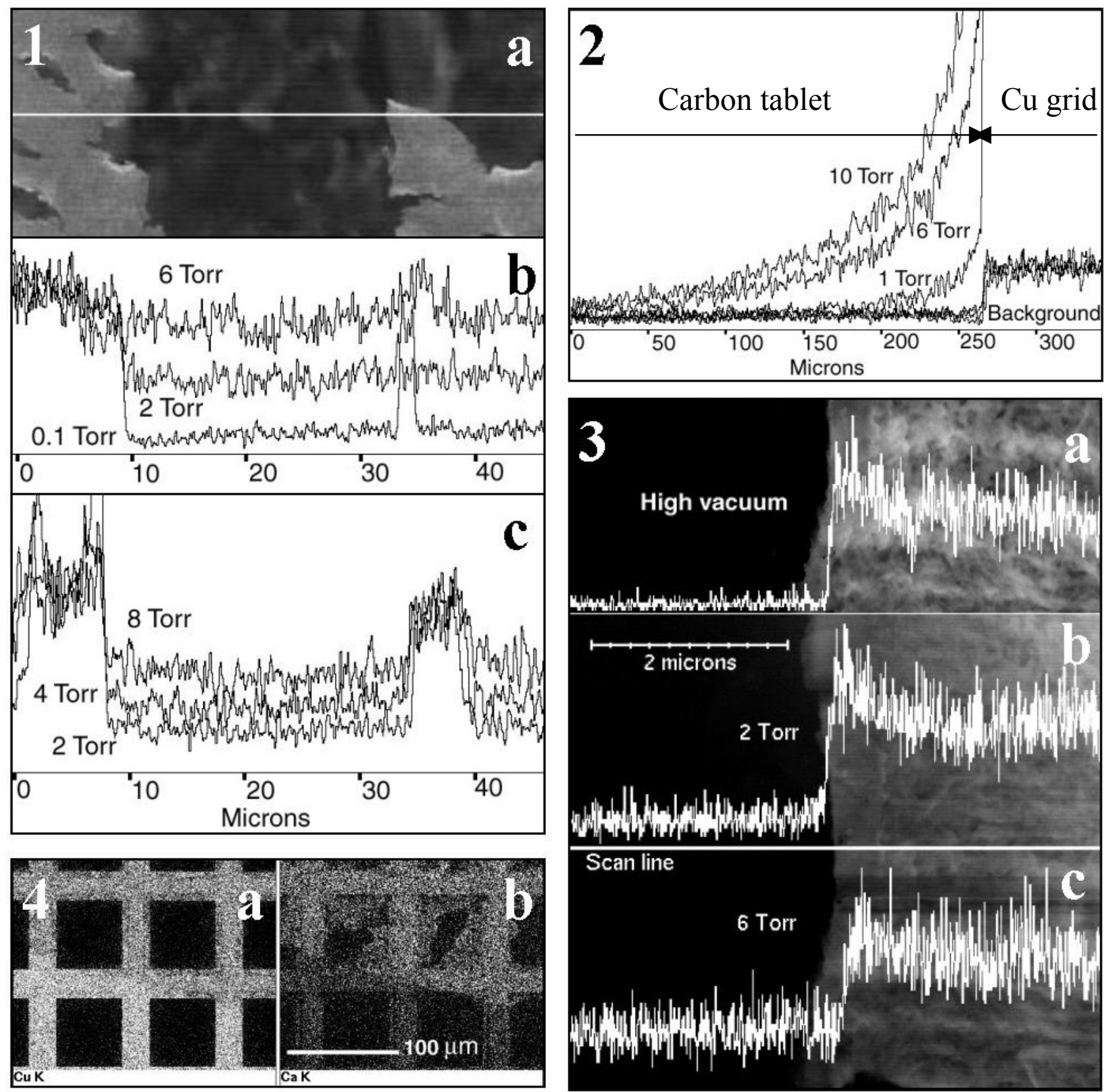

Figure 1. Line profiles of $\mathrm{Ca} \mathrm{K}$ at different pressures. (a) - thin film specimen, (b) - profiles, obtained with standard gaseous SE detector, (c) - profiles, obtained with conical X-ray SE detector.

Figure 2. $\mathrm{Cu} \mathrm{K}$ profiles obtained from $\mathrm{Cu}$ grid placed on carbon and representing tails of stray radiation and edge of $\mathrm{Cu}$ grid. Background acquired at $\mathrm{Ni} \mathrm{K}$ wavelength.

Figure 3. Ca K profiles of a thin film specimen, obtained in conventional high vacuum mode (a) and in wet mode at 2 Torr (b) and 6 Torr (c) pressure.

Figure 4. X-ray maps of a thin film specimen on $\mathrm{Cu}$ grid for $\mathrm{Cu} \mathrm{K}$ (a) and $\mathrm{Ca} \mathrm{K} \mathrm{(b)} \mathrm{(6} \mathrm{Torr).}$ 